\title{
Spondyloepimetaphyseal dysplasia, matrilin-3 type
}

INSERM

\section{Source}

INSERM. (1999). Orphanet: an online rare disease and orphan drug data base.

Spondyloepimetaphyseal dysplasia, matrilin-3 type. ORPHA:156728

Spondyloepimetaphyseal dysplasia, matrilin-3 type is characterized by disproportionate early-onset dwarfism, bowing of the lower limbs, short, wide and stocky long bones with severe epiphyseal and metaphyseal changes, lumbar lordosis, hypoplastic iliac bones, flat ovoid vertebral bodies and normal hands. 